\title{
The validity and reliability of the handheld SW-100 autokeratometer
}

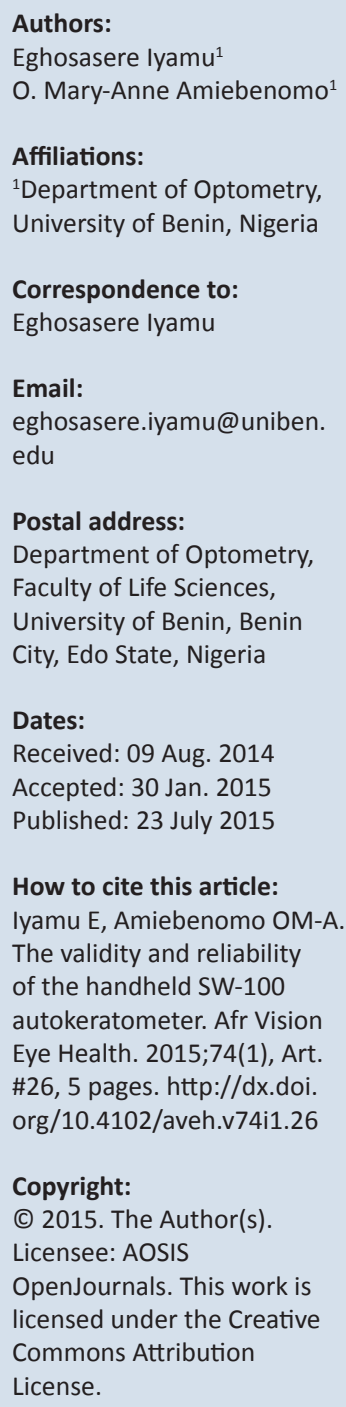

\section{Copyright:}

(C) 2015. The Author(s).

Licensee: AOSIS

OpenJournals. This work is licensed under the Creative Commons Attribution License.

\section{Read online:}

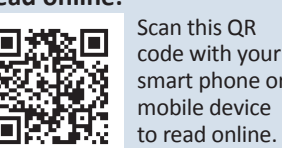

Background: The agreement of new instruments or clinical tests with other instruments or tests defines the possibility of these being used interchangeably.

Aim: To investigate the validity and reliability of the SW-100 autokeratometer using a Bausch \& Lomb (B\&L) keratometer as the 'gold standard'.

Methods: Eighty subjects (80 right eyes) aged between 21 and 38 years were recruited. For intra-test repeatability, two measurements of the corneal radius of curvature were taken with the SW-100 and B\&L keratometers. Forty of the 80 subjects participated in the inter-test repeatability measurement.

Results: Corneal radius of curvature was found to be statistically different between the two instruments $(p<0.001)$, with the SW-100 providing slightly flatter values of $0.11 \mathrm{~mm}$ and $0.05 \mathrm{~mm}$ for the horizontal and vertical meridians, respectively, than the B\&L keratometer. The average corneal curvature was $0.07 \mathrm{~mm}$ flatter with the SW-100 autokeratometer than with the B\&L device. Agreement between the SW-100 and B\&L keratometers' axes was $45 \%$ within $\pm 5^{\circ}, 60.3 \%$ within $\pm 10^{\circ}, 78.8 \%$ within $\pm 15^{\circ}, 80.3 \%$ within $\pm 20^{\circ}$, and $88.7 \%$ within $\pm 40^{\circ}$. Intertest repeatability was better for the B\&L device than the SW-100 and showed no significant difference between the two sessions. Both instruments demonstrated comparable intrasession repeatability. As such, both instruments were comparatively reliable (per coefficients of repeatability). The range of limits of agreement of $\pm 0.14 \mathrm{~mm}$ (horizontal meridian) and $\pm 0.17 \mathrm{~mm}$ (vertical meridian) between the SW-100 and B\&L devices showed good agreement.

Conclusion: The results suggest that the SW-100 autokeratometer is a reliable and objective instrument that, however, provides flatter radii of curvature measurements than the B\&L keratometer. A compensating factor incorporated into the instrument could reduce the difference between the two instruments and make them more interchangeable.

\section{Introduction}

Technological advances are occurring at a rapid rate, as can be seen with the constant production of new instrumentation in ophthalmic practice. The agreement of new instruments or clinical tests with current instruments or tests is an important issue in terms of the possibility of such instruments or clinical procedures being used interchangeably. ${ }^{1}$ Most manual and subjective keratometers such as the Javal-Schiotz and Bausch \& Lomb (Helmholtz) are interchanged with automated devices. The popularity of these automated instruments is attributed to their ability to provide rapid and easy objective measurements over a much larger corneal area than manual keratometers (usually $9 \mathrm{~mm}$ or more versus $3 \mathrm{~mm}$ ). ${ }^{2}$ However, some automated keratometers may measure less than $3 \mathrm{~mm}$ of the cornea. Corneal curvature is measured in clinical practice prior to contact lens fitting (both conventional and customised lenses) by optometrists. The corneal curvature assessment provides very important information for the calculation of intraocular lens (IOL) power before cataract surgery and screening and managing corneal refractive surgery such as laser in situ keratomileusis (LASIK) and photorefractive keratectomy (PRK), ${ }^{3,4}$ and when designing, monitoring and assessing the fit of orthokeratology lenses, and in detection and evaluation of keratoconus. ${ }^{5,6,7,8,9}$ The present study was designed to assess the validity and reliability of the new handheld SW-100 autokeratometer in normals using the manual Bausch \& Lomb keratometer as the 'gold standard'.

\section{Methods}

This observational, prospective, cross-sectional study was conducted in the Optometry Clinic, Department of Optometry, University of Benin, Benin City, Nigeria. The research protocol was approved by the Departmental Research and Ethics Committee in accordance with the tenets of the Declaration of Helsinki. Informed consent was obtained from each subject after thorough 
explanation of the procedure and possible outcomes. All subjects fulfilled the inclusion criteria: at least 21 years of age with no history of corneal pathology, contact lens wear, systemic diseases, ocular trauma or surgery. The corneal radius of curvature of the right eye of each subject was assessed with a Bausch \& Lomb H-135A one-position keratometer (Bausch \& Lomb Corporation, USA). The instrument was calibrated by using a stainless steel ball bearing of $44.75 \mathrm{D}$ power prior to measurements. For the purposes of statistical analysis, measurements were made along the horizontal and vertical meridians instead of the maximum and minimum radii of the eyes concerned. The average corneal radius of curvature was also calculated as the average of the vertical and horizontal radii of curvature (in millimetres). The handheld SW-100 autokeratometer (Shanghai Opnation Industry, China) was calibrated according to the manufacturer's specification. Keratometry with the Bausch \& Lomb (B\&L) was performed by the second author (O.M.A.) whilst the first author (E.I.) performed all autokeratometry. The subjects were randomly assigned to one of the two techniques at a time at each session. The first assessor (E.I.) had no knowledge of the corneal radius of curvature measurement taken by the second assessor for each subject. Prior to measurements with the B\&L device, the eyepiece was adjusted before each reading to avoid introducing accommodative errors, and the instrument was realigned before each measurement. The SW-100 device was held in an upright position and the subject instructed to fixate on the green light at the centre of the device. Four red lights (two horizontal and two vertical) were projected onto the corneal surface, giving rise to the Purkinje image. The Purkinje image was kept within the $15 \mathrm{~mm}$ circle on the screen whilst the distance between the instrument and the cornea was varied from $15 \mathrm{~mm}$ to $40 \mathrm{~mm}$ until horizontal projections were seen on both sides of the mire. This was then accompanied with a beep which increased in frequency as alignment was maintained (to ensure the coincidence of the optical axis of the instrument and visual axis of the observer) and readings taken. The instrument automatically took five readings, and the calculated average of the vertical and horizontal radii of curvature along with the axis were displayed on the LCD screen. Two corneal measurements were taken with the B\&L and SW-100 keratometers and recorded under the first session. Intra-test repeatability of each instrument was determined in all subjects $(N=80$ right eyes). Two measurements were taken for each subject for both the horizontal and vertical meridians, and the withinsubject standard deviation (Sw) ${ }^{1}$ which is a measure of the interval within which $95 \%$ of the measurement differences lie, was obtained by one-way analysis (ANOVA) performed on the measurements. We also calculated the coefficient of repeatability (repeatability limit) using $1.96 \sqrt{2}(2.77) \times \mathrm{Sw}$, which gives the probable limits within which 95\% of measurements should be found. ${ }^{1}$ Inter-test repeatability was estimated by calculating the $p$-value between the first and the second set of measurements that were obtained a week after the initial data on 40 of the original subjects who were willing to participate in this phase.

Statistical analysis was performed with the SPSS software (SPSS, Chicago) for the PC. All data collected were normally distributed (Gaussian) using the Kolmogorov-Smirnov Z test with standardised skewness and standardised kurtosis. Paired data (differences between variables) were assessed with Student's $t$-test and 95\% confidence intervals (CIs) were calculated. The mean difference between methods of measurements (the 'bias') and 95\% limits of agreement (LoA) as the mean difference $( \pm 1.96$ s.d.) were obtained using the Bland-Altman method. ${ }^{10,11}$ Statistical significance was declared when $p \leq 0.05$.

\section{Results}

Eighty students (80 right eyes) from the Department of Optometry at the University of Benin participated in the study. The mean age and s.d. were $25.2 \pm 3.2$ years (range 21-38 years).

Mean astigmatism was $-1.10 \pm 0.65 \mathrm{D}$ for the SW-100 and $-0.87 \pm 0.60 \mathrm{D}$ for the $\mathrm{B} \& \mathrm{~L}$ device, and the maximum values were -3.20 D (SW-100) and -2.35 D (B\&L). For the intertest repeatability study, 40 students participated (40 right eyes; mean age $22.9 \pm 1.6$ years). Mean keratometric values measured with the SW-100 and B\&L keratometers for all subjects for the two principal meridians are given in Table 1. The radius of curvature was flatter along the horizontal meridian with both instruments. The data showed that, on average, the SW-100 gave flatter radii of curvatures than the manual B\&L keratometer.

The agreement between the two instruments (new versus older) assessing the same parameter in a clinical setting is better referred to as the LoA, which describes by how much the methods differ and whether the differences are small enough not to cause any clinical misinterpretation, and therefore may be used interchangeably.

The LoAs are represented by plotting the differences between the two methods for each subject against their means. The mean differences (or biases) of the present study are given in Figures 1 and 2 as approximately $0.11 \mathrm{~mm}$ (95\% CI $-0.03 \mathrm{~mm}-0.24 \mathrm{~mm})$ and $0.05 \mathrm{~mm}(95 \% \mathrm{CI}-0.12 \mathrm{~mm}$ to $0.22 \mathrm{~mm}$ ) for horizontal and vertical meridians, respectively (Table 1). The mean differences (biases) between the SW-100

TABLE 1: Mean ( \pm s.d.) readings (in $\mathrm{mm}$ ) with the SW-100 and Bausch \& Lomb keratometers and $95 \%$ confidence intervals of the mean differences $(N=80$ right eyes of 80 subjects).

\begin{tabular}{|c|c|c|c|c|c|}
\hline Meridional K & SW-100 & B\&L & $p$-value & Mean difference & (95\% confidence interval) \\
\hline Horizontal K & $7.84 \pm 0.12$ & $7.73 \pm 0.12$ & $<0.001$ & 0.11 & $-0.027-0.239$ \\
\hline Vertical K & $7.65 \pm 0.13$ & $7.60 \pm 0.12$ & $<0.001$ & 0.05 & $-0.117-0.217$ \\
\hline Average $\mathrm{K}$ & $7.75 \pm 0.07$ & $7.68 \pm 0.08$ & $<0.001$ & 0.07 & $-0.087-0.227$ \\
\hline
\end{tabular}




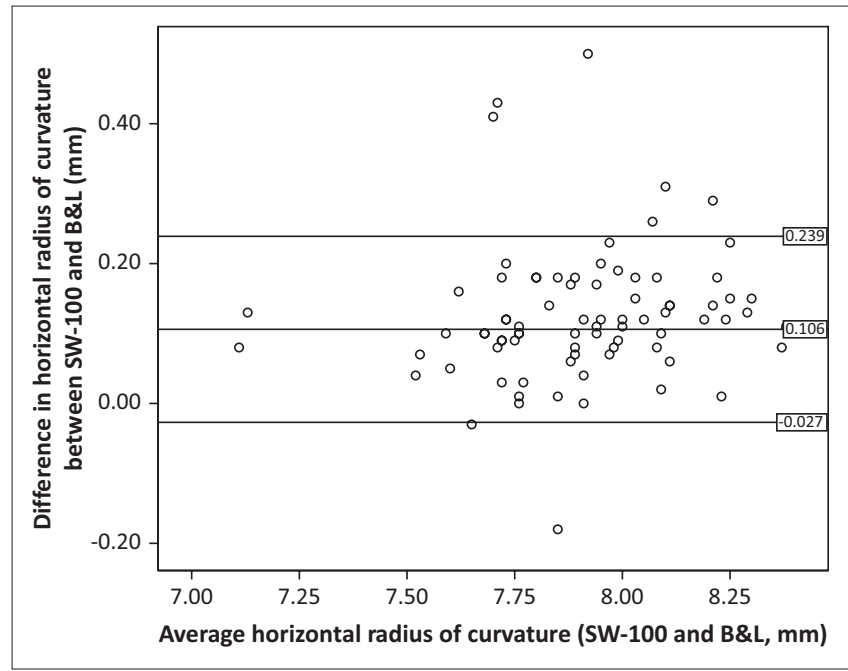

Note: The mean difference or bias is indicated by the middle line; the $95 \%$ limits of agreement are the lines on both sides of the midline.

FIGURE 1: Differences in horizontal radius of curvature between the SW-100 and Bausch \& Lomb keratometers, plotted against the mean horizontal radius of curvature.

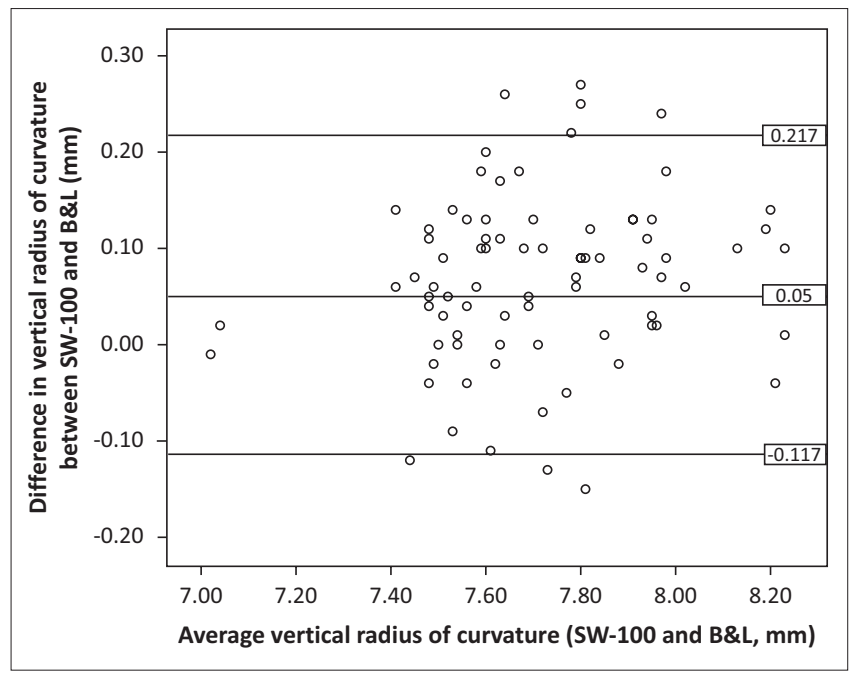

Note: The mean difference is indicated by the middle line; the $95 \%$ limits of agreement are the lines on both sides of the midline.

FIGURE 2: Differences in vertical radius of curvature between the SW-100 and Bausch \& Lomb keratometers, plotted against the mean vertical radii of curvature.

and B\&L devices for the average radii of curvature are given in Figure 3.

The LoAs between the two methods (SW-100 and B\&L keratometers) were $-0.03-0.24$ (or $\pm 0.14 \mathrm{~mm}$ ) for the horizontal meridian and $-0.12-0.22$ (or $\pm 0.17 \mathrm{~mm}$ ) for the vertical meridian. In addition, the LoA between methods was $-0.09-0.23$ (or $\pm 0.16 \mathrm{~mm}$ ) for the average radius of curvature. The means and standard deviations of the two repeated measurements of the curvature of the horizontal and vertical meridians obtained with each instrument in each subject in one session are shown in Table 2.

For the inter-test study, the range of $95 \%$ LoAs are $\pm 0.74 \mathrm{~mm}$ $(1.48 \mathrm{~mm})$ for the vertical radius of curvature, and $\pm 0.76 \mathrm{~mm}$ $(1.52 \mathrm{~mm})$ for the horizontal curvature between the first and

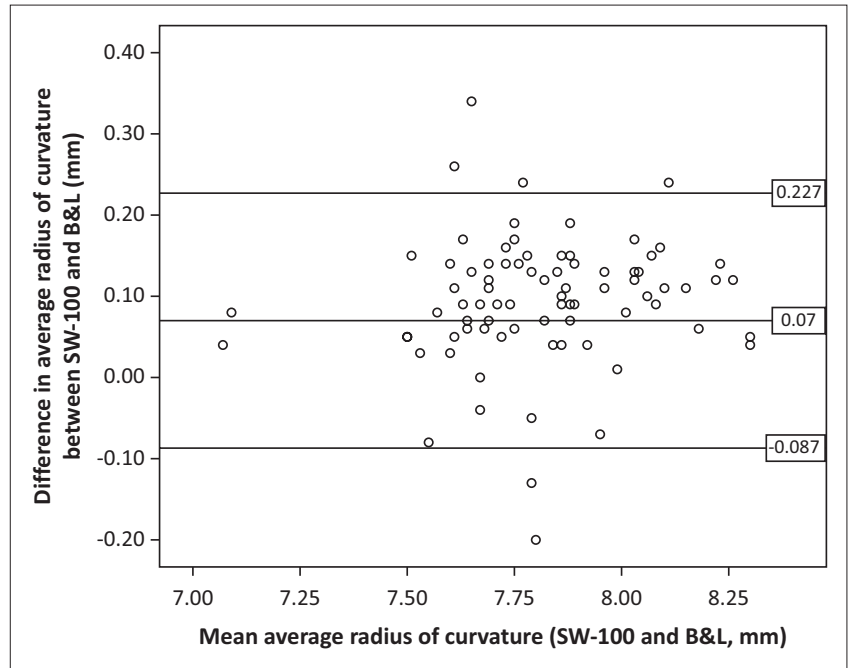

FIGURE 3: Differences in average radius of curvature between SW-100 autokeratometer and Bausch \& Lomb keratometer, plotted against the mean average curvatures of horizontal and vertical meridians.

second sessions with the SW-100 autokeratometer. With the $\mathrm{B} \& \mathrm{~L}$ keratometer, the ranges of LoAs were $\pm 0.67 \mathrm{~mm}$ $(1.34 \mathrm{~mm})$ for vertical and $\pm 0.71 \mathrm{~mm}(1.42 \mathrm{~mm})$ for horizontal curvature between sessions. The mean differences in radius of curvature between two repeated measurements along both meridians with the SW-100 and B\&L devices in the first session was not statistically significant ( $p>0.05$, ANOVA).

The agreement between the SW-100 and B\&L keratometer axes was $45 \%$ within $\pm 5^{\circ}, 60.3 \%$ within $\pm 10^{\circ}, 78.8 \%$ within $\pm 15^{\circ}, 80.3 \%$ within $\pm 20^{\circ}$ and $88.7 \%$ within $\pm 40^{\circ}$.

\section{Discussion}

The ability to determine corneal radius of curvature with a high degree of accuracy and reliability on clinical setting is important to eye care professionals in determining the suitability of contact lens patients. In previous studies, Pearson product moment correlation coefficients were used to assess the agreement between two techniques measuring the same parameter, and this was misleading. ${ }^{1}$ There can be a strong correlation between variables but poor agreement. Correlation coefficients are highly dependent on variability between subjects and cannot detect systematic errors or provide information about under- and/or over-estimation of the measured parameter by any of the methods. BlandAltman analysis ${ }^{10,11}$ is now widely used in comparing two methods that measure the same variable to determine if they can be used interchangeably. In their analysis, emphasis is placed on the 'limit of agreement' technique as it is unlikely that two methods will agree exactly. The LoA describes by how much the two methods under consideration differ and if this difference is small enough to avoid problems with clinical interpretation so that they may be used interchangeably or a new method may replace an older method. ${ }^{1}$

In the present study, it was reported that corneal radius of curvature was statistically different between the two instruments and that the SW-100 provided a slightly flatter 
TABLE 2: Intra-test $(N=80)$ and inter-test $(n=40)$ variability of the curvature results obtained with the SW-100 and Bausch \& Lomb keratometers.

\begin{tabular}{|c|c|c|c|c|c|}
\hline \multirow[t]{2}{*}{ Test } & \multirow[t]{2}{*}{ Assessed parameters } & \multicolumn{2}{|c|}{ SW-100 } & \multicolumn{2}{|c|}{ Bausch \& Lomb } \\
\hline & & Horizontal & Vertical & Horizontal & Vertical \\
\hline \multirow[t]{3}{*}{ Intra-test } & Mean of first session (mm) & 7.83 & 7.65 & 7.73 & 7.6 \\
\hline & Within-subject deviation & 0.22 & 0.22 & 0.22 & 0.2 \\
\hline & Coefficient of repeatability $(1.96 \sqrt{2} \times \mathrm{Sw}=2.77 \times \mathrm{Sw})$ & 0.61 & 0.61 & 0.61 & 0.55 \\
\hline \multirow[t]{3}{*}{ Inter-test } & Mean difference $(\mathrm{mm})$ & -0.03 & -0.005 & -0.01 & -0.001 \\
\hline & s.d. of difference (mm) & 0.15 & 0.14 & 0.13 & 0.12 \\
\hline & $p$-value (between first and second sessions) & 0.45 & 0.6 & 0.55 & 0.63 \\
\hline
\end{tabular}

bias (mean difference between methods) of 0.11 and $0.05 \mathrm{~mm}$ for the horizontal and vertical meridians $(p<0.001)$. For the average corneal radius of curvature, the mean difference between methods of $0.07 \mathrm{~mm}$ was also reported. Shneor et al., ${ }^{2}$ in their study comparing the L80 videokeratographer with the B\&L keratometer, reported a statistically significant steeper bias of $0.05 \mathrm{~mm}$ and $0.07 \mathrm{~mm}$ for horizontal and vertical meridians $(p<0.001)$. The SW-100 autokeratometer measures a wider area of the cornea, greater than the traditional $3 \mathrm{~mm}$ of the $\mathrm{B} \& \mathrm{~L}$ keratometer. The probable reason for the bias between the results of the SW-100 and B\&L keratometers may be attributed to the variation in keratometric measuring procedure of the two instruments including the area measured $(9 \mathrm{~mm}$ versus $3 \mathrm{~mm}$ ). Shneor et $\mathrm{al}^{2}{ }^{2}$ claimed that the discrepancy observed in their study was probably owing to the fact that two different practitioners performed the measurement, and changes in tear film properties that vary continuously throughout the day. In our study, one assessor performed one procedure only throughout the investigation. The mean difference of $0.07 \mathrm{~mm}(0.35 \mathrm{D})$ between the two instruments was clinically significant, and therefore the two methods may not be used interchangeably. This claim was consistent with that of Shneor et al. Shirayama et al. ${ }^{12}$ reported a significant bias in corneal curvature between the IOLMasters and B\&L devices. Similarly, Wang and colleagues ${ }^{13}$ found a significant difference in radii of curvature between the IOLMasters autokeratometer and B\&L keratometer, and that steeper corneal power values were obtained with the IOLMasters. The steeper corneal power values obtained may be related to the more central corneal area of approximately $2.5 \mathrm{~mm}$ diameter assessed by the instrument. In our study, the findings from both instruments indicated flatter curvature along the vertical than the horizontal meridian, which is consistent with the claim that with-the-rule astigmatism is usually seen in a group of young subjects..$^{2,14,15,16}$ The SW-100 autokeratometer gave a mean value flatter by approximately $0.10 \mathrm{~mm}$ in the horizontal and $0.05 \mathrm{~mm}$ in the vertical meridian than the B\&L keratometer. The standard deviations for the horizontal and vertical meridians were almost the same (Table 1) with both instruments, thus indicating a consistent variance along both meridians. ${ }^{2}$ The LoAs between the two instruments were found to be $\pm 0.14 \mathrm{~mm}$ $(-0.03 \mathrm{~mm}-0.24 \mathrm{~mm})$ for the horizontal and $\pm 0.17 \mathrm{~mm}$ $(-0.12 \mathrm{~mm}-0.22 \mathrm{~mm})$ for the vertical meridian. These values were comparable to the LoAs reported by Davies et al. ${ }^{17}$ ( $\pm 0.17 \mathrm{~mm}$ for horizontal, $\pm 0.27 \mathrm{~mm}$ for vertical meridian) and Sheppard and Davies ${ }^{17}( \pm 0.17 \mathrm{~mm}$ for horizontal and $\pm 0.16 \mathrm{~mm}$ for vertical meridian) in their respective studies.
Our LoAs were much narrower than the $\pm 0.35 \mathrm{~mm}$ reported for both meridians by Shneor and colleagues. The validity of an instrument or procedure is generally expressed in terms of agreement with a standard reference..$^{10,18,19}$ The LoAs from the present study, as stated above, showed that the SW-100 autokeratometer demonstrated a good validity compared with the B\&L device. As the SW-100 gave flatter radii of curvature than the $B \& L$ keratometer, it would be more reasonable clinically to incorporate in its software a mathematical offset to the keratometric value of $0.07 \mathrm{~mm}$ (obtained from the average keratometric values). This factor would reduce the mean differences in the horizontal and vertical meridians to $0.03 \mathrm{~mm}$ and $-0.02 \mathrm{~mm}$ with dioptric values less than $0.25 \mathrm{D}$. The ANOVA performed on the two repeated measurements of the radius of curvature along both meridians with the SW-100 and B\&L devices in the first session (intra-test) was not statistically significant $(p>0.05$, ANOVA), indicating a good degree of reliability.

The mean difference in radius of curvature between sessions (inter-test) was $-0.03 \mathrm{~mm}( \pm 0.15)$ for the horizontal meridian and $-0.05 \mathrm{~mm}( \pm 0.14)$ for the vertical meridian with the SW-100 whereas it was between $-0.001 \mathrm{~mm}( \pm 0.13)$ and $-0.01 \mathrm{~mm}( \pm 0.12)$ with the B\&L keratometer for the horizontal and vertical meridians, respectively (Table 2). Consequently, wider standard deviations ranging from 0.12 to $0.15 \mathrm{~mm}$ were reported. From the inter-test repeatability of the SW-100, the instrument demonstrated a good degree of reliability. This scenario was similar to the trend reported by other studies. ${ }^{17,19}$

\section{Conclusion}

Although the range of limits of agreement of $\pm 0.14 \mathrm{~mm}$ (horizontal meridian) and $\pm 0.17 \mathrm{~mm}$ (vertical meridian) between the SW-100 and B\&L devices defined a better agreement, $^{20}$ the mean difference of $0.07 \mathrm{~mm}(0.35 \mathrm{D})$ is greater than the minimum clinical significant value of $0.25 \mathrm{D}$. As clinical interpretation is an essential attribute of this approach, the two devices cannot be used interchangeably. If they are to be used interchangeably, then $0.07 \mathrm{~mm}$ should be considered as a correction factor to modify the readings of the horizontal and vertical curvature of the SW-100 device.

\section{Acknowledgements Competing interests}

The authors declare that they have no financial or personal relationships which may have inappropriately influenced them in writing this article. 


\section{Authors' contributions}

E.I. (University of Benin) conceptual framework; performed autokeratometry; calculations and statistical analysis, manuscript preparation. O.M-A.A. (University of Benin) prepared the subjects or sample for the procedures; performed manual keratometry; grammatical contributions.

\section{References}

1. McAlinden C, Khadka J, Pesudovs K. Statistical methods for conducting agreemen (comparison of clinical tests) and precision (repeatability or reproducibility) studies in optometry and ophthalmology. Ophthal Physiol Opt 2011.31: 330-338. http://dx.doi.org/10.1111/j.1475-1313.2011.00851.x

2. Shneor E, Millodot M, Zyroff M, Gordon-Shaag A. Validation of keratometric measurements obtained with a new integrated aberrometry-topography system. J Optom. 2012;5:80-86. http://dx.doi.org/10.1016/j.optom.2012.03.003

3. Rosa N, De BM, Borrelli M, Filosa ML, Minutillo E, Lanza M. Reliability of the IOLMaster in measuring corneal power changes after hyperopic photorefractive keratectomy. J Refract Surgery. 2011;27:293-298. http://dx.doi.org/10.3928/108 1597X-20100707-01

4. Jinabhai $\mathrm{A}$, Radhakrishnan $\mathrm{H}, \mathrm{O}^{\prime}$ Donnell C. Pellucid corneal marginal degeneration: A review. Cont Lens Anterior Eye. 2011;34:56-63. http://dx.doi.org/10.1016/j. clae.2010.11.007

5. Mountford J, Ruston D, Dave T. Orthokeratology. Oxford: Butterworth-Heinemann; 2004.

6. Gasson A, Morris JA. The contact lens manual - a practical guide to fitting. 4th edn. Edinburgh: Butterworth-Heinemann and Elsevier; 2010. p. 376-386.

7. Assiri AA, Yousuf $B I$, Quantock AJ, Murphy PJ. Incidence and severity of keratoconus in Asir province, Saudi Arabia. Br J Ophthalmol. 2005;89:1403-1406. http://dx.doi.org/10.1136/bjo.2005.074955

8. Jonas JB, Nangia V, Matin A Kulkami M, Bhojwani K. Prevalence and associations of keratoconus in rural Maharashtra in central India: The Central India Eye and Medical Study. Am J Ophthalmol. 2009;148:760-765. http://dx.doi.org/10.1016/j. ajo.2009.06.024
9. Crews MJ, Driebe Jr WT, Stern GA. The clinical management of keratoconus: A 6 year retrospective study. CLAO J. 1994;20:194-197. http://dx.doi.org/10.1097/ 00140068-199407000-00013

10. Bland JM, Altman DG. Statistical methods for assessing agreement between two methods of clinical measurement. Lancet. 1986; 1(8476):307-310. http://dx.doi. org/10.1016/S0140-6736(86)90837-8

11. Bland JM, Altman DG. Measuring agreement in method comparison studies. Stat Methods Med Res. 1999;8:135-160. http://dx.doi.org/10.1191/096228099673 819272

12. Shirayama M, Wang L, Weikert MP, Koch DD. Comparison of corneal powers obtained from 4 different devices. Am J Ophthalmol. 2009;148:528-535. http:// dx.doi.org/10.1016/j.ajo.2009.04.028

13. Wang Q, Savini G, Hoffer KJ, et al. A comprehensive assessment of the precision and agreement of anterior corneal power measurements obtained using 8 different devices. PLoS One. 2012;7:e45607. http://dx.doi.org/10.1371/journal. pone. 0045607

14. Elliott DB. Clinical procedures in primary eye care. 3rd edn. Edinburgh: ButterworthHeinemann and Elsevier; 2007.

15. Koch DD, Wakil JS, Samuelson SW, Haft EA. Comparison of the accuracy and reproducibility of the keratometer and the EyeSys Corneal Analysis System Mode I. J Cataract Refract Surg. 1992;18:342-347. http://dx.doi.org/10.1016/S08863350(13)80068-5

16. Huynh SC, Mai TQ, Kifley A, et al. An evaluation of keratometry in 6-year-old children. Cornea. 2006;25:383-387. http://dx.doi.org/10.1097/01.ico.0000214203. 84081.ec

17. Davies LN, Mallen EA, Wolffsohn JS, Gilmartin B. Clinical evaluation of the Shin-Nippon NVision-K 5001/Grand Seiko WR-5100k autorefractor. Optom Vis Sci. 2003;80:320-324. http://dx.doi.org/10.1097/00006324-20030400000011

18. Sheppard AL, Davies LN. Clinical evaluation of Grand Seiko Autoref/Keratometer WAM-5500. Ophthal Physiol Opt. 2010;30:143-151. http://dx.doi.org/10.1111/ j.1475-1313.2009.00701.x

19. Santodomingo-Rubido J, Mallen EA, Gilmartin B, Wolffsohn JS. A new non-contact optical device for ocular biometry. Br J Ophthalmol. 2002;86:458-462. http:// dx.doi.org/10.1136/bjo.86.4.458

20. Myles PS, Cui J. I. Using the Bland-Altman method to measure agreement with repeated measures. $\mathrm{Br} J$ Anaesthesia. 2007;99:309-311. http://dx.doi. org/10.1093/bja/aem214 